\title{
APLIKASI ALAT UKUR PARTIKULAT DAN SUHU BERBASIS IOT
}

\author{
S. Syahrorini ${ }^{1}$, Dwi Hadidjaja R.S. ${ }^{2}$ \\ ${ }^{1,2}$ Program Studi Teknik Elektro, Fakultas Sains dan Teknologi, \\ Universitas Muhammadiyah Sidoarjo \\ e-mail: ${ }^{1}$ syahrorini@umsida.ac.id, ${ }^{2}$ dwihadidjaja1@umsida.ac.id
}

\begin{abstract}
Human daily life depends on air, so air quality needs to be protected especially against pollution. Decreasing air quality due to dust pollution can result in ARI. Makes it easier to measure ambient air and air temperature using internet-based technology. Designing internetbased dust and temperature measuring devices using the gp2y1010au0f type dust sensor, and DHS11 sensor as a temperature sensor, amplifier circuit, NodemCU microcontroller, and LCD (Liquid Crystal Display). The measurement application is carried out at the location of the PT. Djabus Tunas Utama Ngoro Mojokerto East Java at 10 sampling points around the mixing tube. The measurement results show the concentration carried by ambient air quality standards when the engine stops, so it is safe for employees. When the machine is mixing and the machine is not mixing (ordinary conditions) the concentration of particulates and the temperature exceeds the ambient air quality standard, for that all employees are required to use PPE.
\end{abstract}

Keywords: Dust, Internet, Temperature

\begin{abstract}
Abtrak
Kehidupan sehari-hari manusia tergantung udara, sehingga kualitas udara perlu dijaga tertutama terhadap polusi. Penurunan kualitas udara akibat polusi debu bisa mengakibatkan penyakit ISPA. Mempermudah hasil pengukuran udara ambien dan suhu udara menggunakan teknologi berbasis internet. Perancangan alat ukur debu dan suhu berbasis internet dengan memakai sensor debu type gp2y1010au0f, dan sensor DHS11 sebagai sensor suhu, rangkaian amplifier, mikrokontroler NodemCU, dan LCD (Liquid Crystal Display). Aplikasi pengukuran dilakukan di lokasi PT. Djabus Tunas Utama Ngoro Mojokerto Jatim pada 10 titik sampling disekitar tabung mixing. Hasil pengukuran menunjukkan konsentrasi dibawa baku mutu udara ambien pada saat mesin stop, jadi aman bagi karyawan. Pada saat mesin mixing dan mesin tidak mixing (kondisi biasa) konsentrasi partikulat dan suhu melebihi baku mutu udara ambien, untuk itu semua karyawan diwajibkan menggunakan APD.
\end{abstract}

Kata kunci: Debu, Internet, Suhu

\section{PENDAHULUAN}

Seiring meningkatnya pembangunan di bidang industri, menyebabkan meningkatnya limbah dari proses produksi. Limbah proses produksi berpotensi terjadinya penyebab pencemaran udara, partikel debu, $\mathrm{SO} 2, \mathrm{NO} 2, \mathrm{CO}, \mathrm{NH} 3$ dan $\mathrm{HC}$ [1]. Pencemaran udara dari partikel golongan debu yang bersifat Profilferative dust, jika mengendap dalam paru-paru mengakibatkan terjadinya suatu jaringan parut (fibrosis). Selanjutnya jaringan parut atau (Fibrosis) mengakibatkan adanya pengerasan di jaringan alveoli sehingga bisa mengganggu kerja fungsi paru. Debu Profilferative dust salah satunya berasal dari asbes [2]. Oleh sebab itu perlu dijaga konsentrasi kualitas udara aturan baku mutu udara ambien dengan pemantauan real time. Kualitas udara secara real time diperlukan biaya yang besar, waktu, tenaga, dan teknologi, sehingga perlu inovasi dalam monitoring pengukuran konsentrasi debu udara ambien dan suhu berbasis internet. Peningkatan suhu akan menaikkan kecepatan reaksi suatu bahan kimia. Sedangkan meningkatnya kelembaban relatif dapat meningkatkan suhu 
permukaan bumi, yang dapat menimbulkan peningkatan efek korosif bahan pencemar pada daerah terdampak pencemaran udara [3]

Alat ukur debu dan suhu berbasis internet ini dilakukan pada lokasi pabrik. Hasil pengukuran konsentrasi debu dan suhu ditampilkan pada LCD, NodemCU sebagai kontroller [4][5][6].

Penelitian ini bertujuan mengetahui konsentrasi debu dan suhu saat mesin mixing, mesin tidak mixing (kondisi biasa) dan mesin mixing stop.

\section{RANCANG BANGUN ALAT UKUR}

Pada penelitian ini rancang bangun alat ukur debu dan suhu berbasis internet, selanjutnya diaplikasikan pada lokasi PT. Djabes Tunas Utama.

Dalam rancang bangun alat ukur debu dan suhu berbasis internet memakai komponen: NodemCU dan sensor DHS11, Sensor Sharp Type gp2y1010au0f, ditunjukkan Gambar 1.

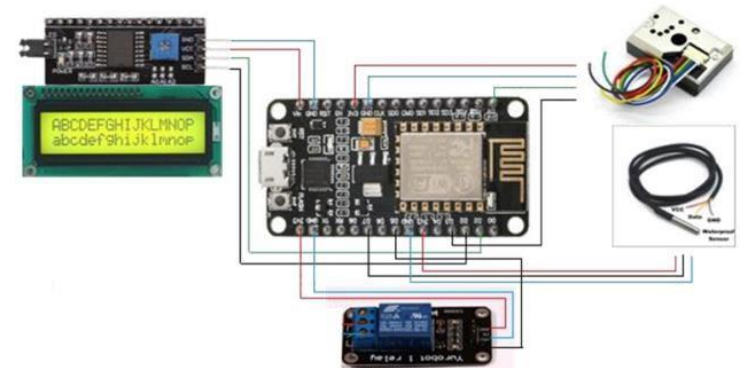

Gambar 1. Wiring Komponen

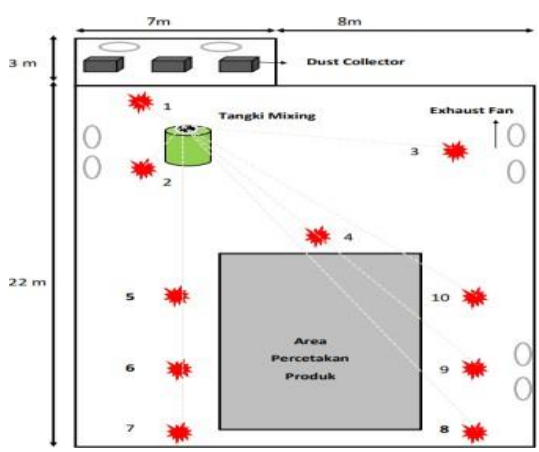

Gambar 2. Denah Lokasi Pengukuran

Gambar 2 menjelaskan denah lokasi pengukuran konsentrasi debu dan suhu di lokasi pabrik, pada 10 titik sampling disekitar tabung mixing. Jarak titik sampling pengukuran ditunjukkan Tabel 1.

Tabel 1. Jarak Titik Sampling Pengukuran

\begin{tabular}{cc}
\hline Titik Pengukuran Sampling & Jarak $(\mathrm{m})$ \\
\hline 1 & 3 \\
2 & 3 \\
3 & 9,5 \\
4 & 7,5 \\
5 & 10 \\
6 & 15 \\
7 & 20 \\
8 & 20,5 \\
9 & 16,5 \\
10 & 14 \\
\hline
\end{tabular}




\section{HASIL PENGAMBILAN DATA}

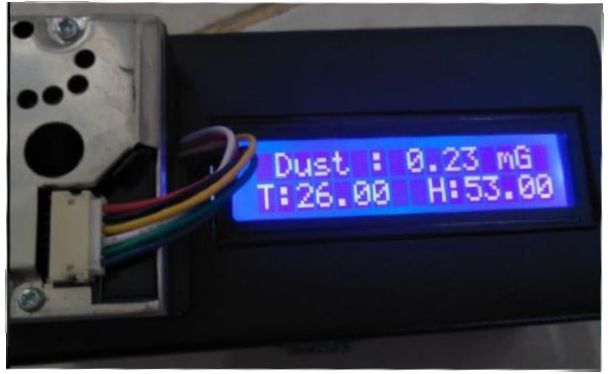

Gambar 3. Tampilan Pada LCD

Gambar 3 menunjukkan tampilan hasil pengukuran debu dan suhu pada layar LCD dengan konsentrasi debu sebesar $0,23 \mathrm{mg}$ dan suhu pengukuran $26^{\circ} \mathrm{C}$. Gambar 4 menunjukkan hasil pengukuran pada smartphone.

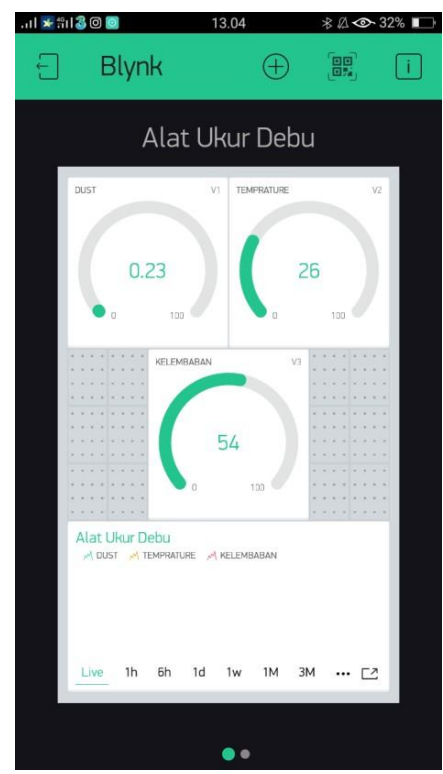

Gambar 4. Tampilan Pada Smartphone

Tabel 2 sampai Tabel 11 menjelaskan pengukuran saat kondisi mixing mesin dari pengukuran satu sampai pengukuran 10, dengan interval tiap menit. Kadar debu saat kondisi mixing mesi 1 sampai 10 adalah terbesar $0,23 \mathrm{mg} / \mathrm{m}^{3}$ pada suhu $39^{\circ} \mathrm{C}$, dan kadar debu terkecil $0,17 \mathrm{mg} / \mathrm{m}^{3}$ pada suhu $38^{\circ} \mathrm{C}$.

Tabel 2. Kondisi Mixing Mesin 1

\begin{tabular}{ccc}
\hline Waktu Pengukuran (Menit) & Konsentrasi Debu & Suhu $\left({ }^{\mathbf{0}} \mathrm{C}\right)$ \\
\hline 1 & 0,23 & 39 \\
2 & 0,21 & 39 \\
3 & 0,21 & 39 \\
4 & 0,21 & 39 \\
5 & 0,21 & 39 \\
\hline \multicolumn{3}{c}{ Tabel 3. Kondisi Mixing Mesin 2 } \\
\hline Waktu Pengukuran (Menit) & Konsentrasi Debu & Suhu $\left({ }^{\mathbf{0}} \mathrm{C}\right)$ \\
\hline 1 & 0,22 & 39 \\
2 & 0,22 & 39 \\
3 & 0,21 & 39 \\
4 & 0,21 & 39 \\
5 & 0,20 & 39 \\
\hline
\end{tabular}


Tabel 4. Kondisi Mixing Mesin 3

\begin{tabular}{ccc}
\hline Waktu Pengukuran (Menit) & Konsentrasi Debu & Suhu $\left({ }^{\mathbf{0}} \mathrm{C}\right)$ \\
\hline 1 & 0,23 & 38 \\
2 & 0,20 & 39 \\
3 & 0,20 & 39 \\
4 & 0,19 & 38 \\
5 & 0,19 & 38 \\
\hline
\end{tabular}

Tabel 5. Kondisi Mixing Mesin 4

\begin{tabular}{ccc}
\hline Waktu Pengukuran (Menit) & Konsentrasi Debu & Suhu $\left({ }^{\mathbf{0}} \mathrm{C}\right)$ \\
\hline 1 & 0,20 & 39 \\
2 & 0,19 & 39 \\
3 & 0,20 & 39 \\
4 & 0,20 & 39 \\
5 & 0,20 & 38 \\
\hline
\end{tabular}

Tabel 6. Kondisi Mixing Mesin 5

\begin{tabular}{ccc}
\hline Waktu Pengukuran (Menit) & Konsentrasi Debu & Suhu $\left({ }^{\mathbf{0}} \mathrm{C}\right)$ \\
\hline 1 & 0,20 & 38 \\
2 & 0,20 & 38 \\
3 & 0,20 & 38 \\
4 & 0,20 & 39 \\
5 & 019 & 38 \\
\hline
\end{tabular}

Tabel 7. Kondisi Mixing Mesin 6

\begin{tabular}{ccc}
\hline Waktu Pengukuran (Menit) & Konsentrasi Debu & Suhu $\left({ }^{\mathbf{0}} \mathrm{C}\right)$ \\
\hline 1 & 0,19 & 38 \\
2 & 0,19 & 39 \\
3 & 0,19 & 38 \\
4 & 0,19 & 39 \\
5 & 0,19 & 39 \\
\hline
\end{tabular}

Tabel 8. Kondisi Mixing Mesin 7

\begin{tabular}{ccc}
\hline Waktu Pengukuran (Menit) & Konsentrasi Debu & Suhu $\left({ }^{\mathbf{0}} \mathrm{C}\right)$ \\
\hline 1 & 0,18 & 38 \\
2 & 0,19 & 38 \\
3 & 0,18 & 38 \\
4 & 0,18 & 38 \\
5 & 0,18 & 38 \\
\hline
\end{tabular}

Tabel 9. Kondisi Mixing Mesin 8

\begin{tabular}{ccc}
\hline Waktu Pengukuran (Menit) & Konsentrasi Debu & Suhu $\left({ }^{\mathbf{0}} \mathrm{C}\right)$ \\
\hline 1 & 0,18 & 38 \\
2 & 0,18 & 38 \\
3 & 0,17 & 38 \\
4 & 0,17 & 38 \\
5 & 0,17 & 38 \\
\hline
\end{tabular}


Tabel 10. Kondisi Mixing Mesin 9

\begin{tabular}{ccc}
\hline Waktu Pengukuran (Menit) & Konsentrasi Debu & Suhu $\left({ }^{\mathbf{0}} \mathrm{C}\right)$ \\
\hline 1 & 0,17 & 38 \\
2 & 0,18 & 38 \\
3 & 0,18 & 38 \\
4 & 0,18 & 38 \\
5 & 0,18 & 38 \\
\hline \multicolumn{3}{c}{ Tabel 11. Kondisi Mixing Mesin 10 } \\
\hline Waktu Pengukuran (Menit) & Konsentrasi Debu & Suhu $\left({ }^{\mathbf{0}} \mathrm{C}\right)$ \\
\hline 1 & 0,18 & 39 \\
2 & 0,18 & 39 \\
3 & 0,18 & 39 \\
4 & 0,18 & 38 \\
5 & 0,18 & 38 \\
\hline
\end{tabular}

Tabel 12 sampai Tabel 21 menjelaskan hasil pengukuran titik sampling pada kondisi mesin tidak mixing (biasa), dilakukan pengukuran 10 titik sampling dengan lima kali pengukuran interval waktu tiap menit. Kadar debu hasil pengukuran terbesar terbesar 0,21 $\mathrm{mg} / \mathrm{m} 3$ pada suhu $39^{\circ} \mathrm{C}$, dan kadar debu terkecil.

Tabel 12. Kondisi Mesin Tidak Mixing (Kondisi Biasa) 1

\begin{tabular}{ccc}
\hline Waktu Pengukuran & Kadar Debu & Suhu $\left({ }^{\mathbf{0}} \mathrm{C}\right)$ \\
\hline 1 & 0,20 & 39 \\
2 & 0,19 & 39 \\
3 & 0,19 & 38 \\
4 & 0,19 & 38 \\
5 & 0,18 & 38 \\
\hline
\end{tabular}

Tabel 13. Kondisi Mesin Tidak Mixing (Kondisi Biasa) 2

\begin{tabular}{ccc}
\hline Waktu Pengukuran & Kadar Debu & Suhu $\left({ }^{\mathbf{0}} \mathrm{C}\right)$ \\
\hline 1 & 0,17 & 39 \\
2 & 0,21 & 39 \\
3 & 0,21 & 39 \\
4 & 0,21 & 39 \\
5 & 0,19 & 38 \\
\hline
\end{tabular}

Tabel 14. Kondisi Mesin Tidak Mixing (Kondisi Biasa) 3

\begin{tabular}{ccc}
\hline Waktu Pengukuran & Kadar Debu & Suhu $\left({ }^{\mathbf{0}} \mathrm{C}\right)$ \\
\hline 1 & 0,17 & 38 \\
2 & 0,17 & 38 \\
3 & 0,17 & 38 \\
4 & 0,17 & 39 \\
5 & 0,18 & 38 \\
\hline
\end{tabular}

Tabel 15. Kondisi Mesin Tidak Mixing (Kondisi Biasa) 4

\begin{tabular}{ccc}
\hline Waktu Pengukuran & Kadar Debu & Suhu $\left({ }^{\mathbf{0}} \mathrm{C}\right)$ \\
\hline 1 & 0,18 & 38 \\
2 & 0,18 & 38 \\
3 & 0,18 & 38 \\
4 & 0,19 & 38 \\
5 & 0,19 & 38 \\
\hline
\end{tabular}


Tabel 16. Kondisi Mesin Tidak Mixing (Kondisi Biasa) 5

\begin{tabular}{ccc}
\hline Waktu Pengukuran & Kadar Debu & Suhu $\left({ }^{\mathbf{0}} \mathrm{C}\right)$ \\
\hline 1 & 0,18 & 38 \\
2 & 0,18 & 38 \\
3 & 0,18 & 38 \\
4 & 0,19 & 38 \\
5 & 0,18 & 38 \\
\hline
\end{tabular}

Tabel 17. Kondisi Mesin Tidak Mixing (Kondisi Biasa) 6

\begin{tabular}{ccc}
\hline Waktu Pengukuran & Kadar Debu & Suhu $\left({ }^{\mathbf{O}} \mathrm{C}\right)$ \\
\hline 1 & 0,18 & 38 \\
2 & 0,18 & 38 \\
3 & 0,18 & 38 \\
4 & 0,18 & 38 \\
5 & 0,19 & 38 \\
\hline
\end{tabular}

Tabel 18. Kondisi Mesin Tidak Mixing (Kondisi Biasa) 7

\begin{tabular}{ccc}
\hline Waktu Pengukuran & Kadar Debu & Suhu $\left({ }^{\mathbf{0}} \mathrm{C}\right)$ \\
\hline 1 & 0,18 & 39 \\
2 & 0,18 & 38 \\
3 & 0,18 & 38 \\
4 & 0,18 & 38 \\
5 & 0,18 & 38 \\
\hline
\end{tabular}

Tabel 19. Kondisi Mesin Tidak Mixing (Kondisi Biasa 8

\begin{tabular}{ccc}
\hline Waktu Pengukuran & Kadar Debu & Suhu $\left({ }^{\mathbf{0}} \mathrm{C}\right)$ \\
\hline 1 & 0,18 & 39 \\
2 & 0,17 & 38 \\
3 & 0,17 & 38 \\
4 & 0,17 & 39 \\
5 & 0,17 & 38 \\
\hline
\end{tabular}

Tabel 20. Kondisi Mesin Tidak Mixing (Kondisi Biasa) 9

\begin{tabular}{ccc}
\hline Waktu Pengukuran & Kadar Debu & Suhu $\left({ }^{\mathbf{0}} \mathrm{C}\right)$ \\
\hline 1 & 0,18 & 38 \\
2 & 0,17 & 39 \\
3 & 0,17 & 38 \\
4 & 0,17 & 39 \\
5 & 0,18 & 38 \\
\hline
\end{tabular}

Tabel 21. Kondisi Mesin Tidak Mixing (Kondisi Biasa) 10

\begin{tabular}{ccc}
\hline Waktu Pengukuran & Kadar Debu & Suhu $\left({ }^{\mathbf{0}} \mathrm{C}\right)$ \\
\hline 1 & 0,18 & 38 \\
2 & 0,18 & 38 \\
3 & 0,18 & 38 \\
4 & 0,18 & 39 \\
5 & 0,18 & 37 \\
\hline
\end{tabular}

Tabel 22 sampai Tabel 31 menjelaskan hasil pengukuran titik sampling pada kondisi mesin stop, dilakukan pengukuran 10 titik sampling dengan lima kali pengukuran interval waktu tiap menit. Kadar debu hasil pengukuran terbesar terbesar $0,14 \mathrm{mg} / \mathrm{m}^{3}$ pada suhu $31^{\circ} \mathrm{C}$, dan kadar debu terkecil $0,08 \mathrm{mg} / \mathrm{m}^{3}$ pada suhu $30^{\circ} \mathrm{C}$. 
Tabel 22. Kondisi Mesin Stop 1

\begin{tabular}{ccc}
\hline Waktu Pengukuran & Kadar Debu & Suhu $\left({ }^{\mathbf{0}} \mathrm{C}\right)$ \\
\hline 1 & 0,14 & 31 \\
2 & 0,14 & 31 \\
3 & 0,14 & 31 \\
4 & 0,13 & 31 \\
5 & 0,13 & 31 \\
\hline
\end{tabular}

Tabel 23. Kondisi Mesin Stop 2

\begin{tabular}{ccc}
\hline Waktu Pengukuran & Kadar Debu & Suhu $\left({ }^{\mathbf{0}} \mathrm{C}\right)$ \\
\hline 1 & 0,11 & 31 \\
2 & 0,11 & 31 \\
3 & 0,12 & 31 \\
4 & 0,12 & 31 \\
5 & 0,12 & 31 \\
\hline
\end{tabular}

Tabel 24. Kondisi Mesin Stop 3

\begin{tabular}{ccc}
\hline Waktu Pengukuran & Kadar Debu & Suhu $\left({ }^{\mathbf{O}} \mathrm{C}\right)$ \\
\hline 1 & 0,10 & 31 \\
2 & 0,10 & 31 \\
3 & 0,10 & 31 \\
4 & 0,11 & 31 \\
5 & 0,10 & 31 \\
\hline
\end{tabular}

Tabel 25. Kondisi Mesin Stop 4

\begin{tabular}{ccc}
\hline Waktu Pengukuran & Kadar Debu & Suhu $\left({ }^{\mathbf{O}} \mathrm{C}\right)$ \\
\hline 1 & 0,13 & 31 \\
2 & 0,13 & 31 \\
3 & 0,13 & 31 \\
4 & 0,13 & 31 \\
5 & 0,12 & 38 \\
\hline
\end{tabular}

Tabel 26. Kondisi Mesin Stop 5

\begin{tabular}{ccc}
\hline Waktu Pengukuran & Kadar Debu & Suhu $\left({ }^{\mathbf{0}} \mathrm{C}\right)$ \\
\hline 1 & 0,12 & 30 \\
2 & 0,12 & 30 \\
3 & 0,12 & 30 \\
4 & 0,12 & 31 \\
5 & 0,12 & 31 \\
\hline
\end{tabular}

Tabel 27. Kondisi Mesin Stop 6

\begin{tabular}{ccc}
\hline Waktu Pengukuran & Kadar Debu & Suhu $\left({ }^{\mathbf{0}} \mathrm{C}\right)$ \\
\hline 1 & 0,11 & 31 \\
2 & 0,10 & 31 \\
3 & 0,10 & 31 \\
4 & 0,09 & 31 \\
5 & 0,09 & 31 \\
\hline
\end{tabular}


Tabel 28. Kondisi Mesin Stop 7

\begin{tabular}{ccc}
\hline Waktu Pengukuran & Kadar Debu & Suhu $\left({ }^{\mathbf{0}} \mathrm{C}\right)$ \\
\hline 1 & 0,10 & 31 \\
2 & 0,10 & 31 \\
3 & 0,10 & 30 \\
4 & 0,09 & 30 \\
5 & 0,09 & 30 \\
\hline
\end{tabular}

Tabel 29. Kondisi Mesin Stop 8

\begin{tabular}{ccc}
\hline Waktu Pengukuran & Kadar Debu & Suhu $\left({ }^{\mathbf{0}} \mathrm{C}\right)$ \\
\hline 1 & 0,09 & 30 \\
2 & 0,08 & 30 \\
3 & 0,09 & 30 \\
4 & 0,08 & 30 \\
5 & 0,08 & 30 \\
\hline
\end{tabular}

Tabel 30. Kondisi Mesin Stop 9

\begin{tabular}{ccc}
\hline Waktu Pengukuran & Kadar Debu & Suhu $\left({ }^{\mathbf{0}} \mathrm{C}\right)$ \\
\hline 1 & 0,08 & 30 \\
2 & 0,08 & 30 \\
3 & 0,08 & 30 \\
4 & 0,09 & 30 \\
5 & 0,09 & 30 \\
\hline
\end{tabular}

Tabel 31. Kondisi Mesin Stop 10

\begin{tabular}{ccc}
\hline Waktu Pengukuran & Kadar Debu & Suhu $\left({ }^{\mathbf{O}} \mathrm{C}\right)$ \\
\hline 1 & 0,09 & 31 \\
2 & 0,10 & 31 \\
3 & 0,10 & 31 \\
4 & 0,10 & 31 \\
5 & 0,10 & 31 \\
\hline
\end{tabular}

\section{KESIMPULAN}

Berdasarkan aplikasi alat ukur debu dan suhu berbasis IoT dapat disimpulkan sebagai berikut:

Alat monitoring kadar debu bekerja sesuai dengan yang diharapkan. Terbukti dengan sensor yang telah mendeteksi kadar debu dengan presisi dan dapat mengirim data yang selanjutnya akan ditampilkan pada LCD dan smartphone.

Untuk sensor suhu meski hasil output pengukuran memiliki selisih dibanding pengukuran yang telah dilakukan sebelumnya namun tidak terlalu signifikan dan alat ini tetap bekerja sesuai harapan yaitu tidak lebih dari $30^{\circ} \mathrm{C}-39^{\circ} \mathrm{C}$

Prinsip kerja alat ini sebagai pengendali kadar debu dan temperatur diproses oleh kinerja sensor dan selanjutnya akan ditampilkan pada alat monitoring.

\section{DAFTAR PUSTAKA}

[1] Mukono, H., J., 2008, Pencemaran Udara dan Pengaruhnya Terhadap Gangguan Saluran Pernafasan (Air Pollution and Its Influence on Respiratory Disorders), Airlangga University Press, Surabaya.

[2] Munthe, E., Yunus, F., Wiyono, W., H., Ikhsan M., 2003, Pengaruh Inhalasi Sulfur Oksida Terhadap Paru Cermin Kedokteran: 138: 
http://journal.unair.ac.id/downloadfull/KESLING8628- 3d95e64d75fullabstract.pdf, p. 29-233, diakses May 2018

[3] Syahrorini1, S., Rahmansyah, A., Pramono, S., H., Soemarno. 2017, Computer Simulation Of The Dispersion Gaussian Model Of Sugar Factory Particulate, Asian Conference on Industrial Technology and Integrated Engineering (ACITIE2017)

[4] Syahrorini S., Mafatihul A., E., A., 2017, Alat Pendeteksi Debu Dengan Menggunakan Arduino Uno Dan Berbasis SMS Gateway, Skripsi, Teknik Elekrto, Fakultas Teknik, Universitas Muhammadiyah Sidoarjo

[5] S. Syahrorini, Akhmad Ahfas. 2017 "Penyebaran Partikulat Kawasan Pabrik Gula Krembung", https://journal.uny.ac.id/index.php/elinvo/article/download/19241/10926, diakses tanggal May 2018

[6] Syahrorini., S., Hadidjaja, D., Ahfas, A., Rahmansyah, A., Purnomo, S.,H., 2018, Design Measuring Instrument Dust Based Internet Of Things, iopscience.iop.org/article/10.1088/1757-899X/434/1/.../pdf, diakses May 2018

[7] Syahrorini1, S., Rahmansyah, A., Pramono, S., H., Soemarno, 2018, Distribution Model of Particulate Dust From Chimney of Sidoarjo Sugar Factory, https://jpal.ub.ac.id/index.php/jpal/article/viewFile/353/- 269, JPAL Vol. 9, No. 2, diakses May 2018

[8] Soemirat S., 2004. "Kesehatan Lingkungan", Gadjah mada University Press

[9] Pudjiastuti, W., 2002, Debu Sebagai Bahan Pencemar yang Menbahayakan Kesehatan Kerja, http://www.Depkes.go.id/debuPDF,/ diakses 6 April 2012

[10] Ruslindah, Y., Dawati, H., Fitria, D., 2009, Karakteristik Fisik dan Kimia Partikulat Kota Padang, repo.unand.ac.id/2914/, diunduh 19 April 2013

[11] DepKes. Republik Indonesia, 1993, Upaya Kesehatan Kerja Sektor In Formal Di Indonesia Cetakan ke 2, Gunung Agung Jakarta 